This is the author's final, peer-reviewed manuscript as accepted for publication. The publisher-formatted version may be available through the publisher's web site or your institution's library.

\title{
Investing in the curricular lives of educators: narrative inquiry as pedagogical medium
}

Margaret Macintyre Latta, Jeong-Hee Kim

\section{How to cite this manuscript}

If you make reference to this version of the manuscript, use the following information:

Latta, M. M., \& Kim, J. (2011). Investing in the curricular lives of educators: Narrative inquiry as pedagogical medium. Retrieved from http://krex.ksu.edu

\section{Published Version Information}

Citation: Latta, M. M., \& Kim, J. (2011). Investing in the curricular lives of educators: Narrative inquiry as pedagogical medium. Journal of Curriculum Studies, 43(5), 679695.

Copyright: ㄷ 2011 Taylor \& Francis

Digital Object Identifier (DOI): doi:10.1080/00220272.2011.609566

Publisher's Link: http://www.tandfonline.com/doi/abs/10.1080/00220272.2011.609566

This item was retrieved from the K-State Research Exchange (K-REx), the institutional repository of Kansas State University. K-REx is available at http://krex.ksu.edu 
Investing in the Curricular Lives of Educators:

Narrative Inquiry as Pedagogical Medium

\author{
Margaret Macintyre Latta \\ University of Nebraska, Lincoln \\ Jeong-Hee Kim \\ Kansas State University
}




\begin{abstract}
This paper draws on the experiences of two graduate level curriculum theory classes taught at different teacher education institutions in the United States. As teacher educators and curriculum theorists, we invest in creating reflexive spaces for teachers to explore the complex terrain of lived curriculum. Narrative inquiry is chronicled as acting as an important pedagogical medium toward this aim. The purpose of the paper is to explore what practicing teachers' narratives reveal about their curricular roles in relation to theory and practice. As participating educators consider their associated teaching identities, phenomenological notions of place are found to be fitting as they navigate understandings of lived curriculum as situated, thoughtful, and intentional. Insights generated through reflexive analysis manifest three thematic intersections: 1) Teachers confronting dissonance between theory and practice as teaching identity displacement; 2) Teachers negotiating greater implacement; and 3) Teachers moving toward embodying the creative space for teaching and learning. Renewed roles surface for teacher educators and curriculum theorists, challenging all involved to purposefully foster contexts for professional learning rather than subservience, and claim the responsibilities to provide the intellectual, emotional, and pragmatic spaces where teachers' lived curriculum efforts can be developed and nurtured.
\end{abstract}

Keywords: curriculum theorizing, teacher education, professional knowledge, and narrative inquiry. 


\section{Introduction}

We are both teacher educators and curriculum theorists invested in exploring and navigating the complex nature of curriculum alongside practicing educators enrolled in graduate coursework at our respective institutions. Our concern is to occasion lived understandings of curriculum as genuine inquiry into what is worth knowing, rather than simply a curricular document. Curriculum restored to its etymological roots of 'currere' invests in prompting, sustaining, and nurturing a movement of thinking in self and other(s). In doing so, it forms the 'complicated conversation' that Pinar (2009:11) states characterizes lived curriculum. Providing access to, and deliberately considering the features and significances of complicated curricular conversations becomes our shared commitment. We invest in cultivating lived understandings of curricular practices as concomitantly situated, thoughtful, and intentional. Situatedness entails deliberately attending to the particulars of students, contexts, and subject matter. Thoughtfulness entails attending to the creation of learning deemed fitting for the given particularities. Intentionality entails assuming and seeking relatedness and connectedness among teacher/student/subject matter. Narrative inquiry opens up a curricular space enabling our efforts.

Situated, thoughtful, and intentional teaching and learning assumes curricular experiences are complex, dynamic, and in flux. Teaching and learning encountered as such, is always at the nexus of action and place. It is this nexus that forms what Dewey (1934: 44) terms the 'undergoings' and 'doings', the relational complexities, demanding and deserving attention. The ongoing teacher 
discernment within this movement is the curricular task we embark upon. As educators attempt to embrace this task in graduate coursework with us, they relay how they find themselves rarely asking what ought to count as knowledge or what teaching for understanding might feel and look like in practice. Embodied inner tensions surface in course discussions as they struggle to articulate the underlying reasons. Educators confront and acknowledge how dismissing some students, ideas, differences, and questions is problematic and unsettling, and yet there is much about their school contexts that is in tension with these matters. They further describe a detached teaching identity that takes over that educators do not necessarily feel at ease with, but concede it becomes a survival mode that entraps them.

There is much about the notion of a detached teaching identity that resonates with us. Increasingly, we find ourselves struggling to negotiate the needed spaces and circumstances for occasioning and developing situated, thoughtful, and intentional curriculum in the lives of the educators we meet in our graduate courses. The research literature indicates we are not alone and that this struggle is of global concern. For example, Hargreaves and Shirley (2009) look back at Lortie's (1975) sociological study, Schoolteacher, which argued that the improvement of education was hindered by short sighted thinking focused on a presentism consuming a teacher's practices and capacities to extend and deepen learning opportunities for students. The persistence of presentism is then traced into current times. In particular, Hargreaves and Shirley's study of 300 under performing secondary schools in the United Kingdom purposefully 
engaged in educational change, finds presentism to persist in endemic and adaptive forms. Further, presentism is found to morph into an addictive form where all involved cannot envision teaching/learning contexts beyond the narrow immediacy of achievement scores and gaps.

Akin to Hargreaves and Shirley (2009) challenge to presentism, Pinar (2009) challenges the notions of subjectivity and education as ways we must open up and cultivate cosmopolitanism for learning and living in the world well with others. He insists teachers must devise the curriculum they teach providing 'passages between the past and the future, between subjectivity and society, the local and the global' (p. 51). And, Smith (2006) relays the misinformation he sees controlling how we live and act in the world and causing a crises of pedagogy. The necessity of room for teacher and students to be freed 'from the cage of subjectivity that their own immediate environments [including class, tribe, or nation] have constructed for them' (p. 80) is outlined.

Groundwater-Smith and Mockler (2009) similarly examine the current problems of teacher professional learning and the needed knowledge and associated agency to address these concerns in an age of compliance. They argue for professional judgment and freedom and identify a first step as 'redeveloping the professional confidence of teachers' (p. 138).

Kemmis and Smith (2008) also invest in the professional confidence of teachers and articulate what they term a radical proposal reorienting education to enable teachers' praxis understood as 'contributing to the good for humankind'( $p$. 
287). The lived consequences for teachers, students, subject matter, and milieu orient toward learning relationships, connections, and possibilities.

In our roles as teacher educators and curriculum theorists we share the global concerns noted by these authors and fear losing sight of lived curriculum and its ensuing significances alongside practicing teachers. Our hope is that the coursework we offer occasions multiple opportunities for educators to see and hear who they are as teachers so each can see and hear their students as the necessary curricular investment at the core of teaching/learning.

The purpose of our paper is, then, to explore what practicing teachers reveal in relation to theory and practice concerning lived curriculum engaged as situated, thoughtful, and intentional. Additionally, we hope to gain insights into renewed roles for teacher educators in enabling greater cognizance of the nature and significances of lived curriculum in the lives of all involved.

\section{Research Context}

We each conduct a semester-long, graduate curriculum theory course over 16 weeks in a seminar format at two different institutions where practicing K16 educators engage in reading and dialoguing about the nature of lived curriculum in relation to curriculum theory. The two graduate level curriculum theory classes are used for data collection for our study. Parts of both course syllabi were shared between the classes (e.g. some readings and assignments

are the same). Both classes were also provided an opportunity to meet via Polycom and directly converse with each other across institutions during two weeks of class time. These conversations were recorded. The number of 
participants is 8 from one class, and 11 from the other class. Neither of us knew the number or identification of the voluntary participants in our joint inquiry until the course was complete and grades were assigned. Participants' background information is provided in table 1 below.

table 1 Participants

\begin{tabular}{|c|c|c|c|}
\hline & Number of Students & Level of Teaching & Level of Education \\
\hline Class A & $\begin{array}{l}-7 \text { female students; } \\
-1 \text { male student }\end{array}$ & $\begin{array}{l}-1 \text { elementary; } \\
-3 \text { middle/high school; } \\
-4 \text { former high school } \\
\text { teachers now teaching } \\
\text { part-time at the college } \\
\text { level }\end{array}$ & $\begin{array}{l}-1 \text { working on } \\
\text { master's degrees; } \\
-7 \text { working on } \\
\text { doctoral degrees }\end{array}$ \\
\hline Class B & $\begin{array}{l}-9 \text { female students } \\
-2 \text { male students }\end{array}$ & $\begin{array}{l}-1 \text { early childhood } \\
-7 \text { middle/high school } \\
-3 \text { college level }\end{array}$ & $\begin{array}{l}-8 \text { working on } \\
\text { master's degrees; } \\
-3 \text { working on } \\
\text { doctoral degrees. }\end{array}$ \\
\hline
\end{tabular}

Data is collected through common expectations across both courses for all course participants. These include:

1) Researcher/Instructor field texts documenting the interchange across all participants and texts on an ongoing basis elucidating theory/practice relations throughout the duration of the course including instructors' weekly written responses to student narratives, instructor planning documents, and in-class discussion forums.

2) Documentation of opportunities created for educators to concretely experience lived theory within the unfolding of the course itself and to incite educators to locate and experience these opportunities within their own teaching/learning practices. 
3) Educators' weekly narrative accounts of theory/practice relations in connection with critical teaching/learning incidents.

4) The research literature situating the inquiry and the traditions inherited and being reconstructed.

Throughout these seminars we agree to acquaint participants with the predominant perspectives in the curriculum field and the scholars who represent them. In particular, we choose to examine how the reconceptualized field of curriculum as the scholarly and disciplined understanding of educational experience understood in Deweyan (1938) terms as occurring at the nexus of 'situation' and 'interaction', is always in the making. A number of themes pervading the reconceptualists' concerns and re-forming post-reconceptualists' concerns are shared across both courses (see Malewski, 2010). For example, the role of school in a pluralistic and changing society; the need, desire, and right of teachers and others to participate in curriculum decision-making and the considerations related to that process; and the lived consequences for learners, learning, teachers, and teaching associated with lived curriculum as situational, intentional, and thoughtful. Both seminars examine these themes from the standpoint of a variety of theoretical orientations purposefully selected to enable educators to locate and respond to the relational complexities, the undergoings and doings, of their classrooms. We ask all participating educators to risk undertaking new thinking/initiatives on an ongoing basis.

The course syllabi state that participants will be expected to write weekly narratives bridging the theoretical readings across the curriculum field with their 
own concrete curricular experiences. In other words, participants are asked to 'work the ideas' (Uhrmacher \& Matthews, 2005), and share their theorizing with each other on a continual basis to inform and grow everyone's efforts toward greater agency for their students' learning. We are upfront from the beginning of each course that as teacher educators and researchers we are interested in studying the conduct of these efforts and formal approval to do so is in place via Institutional Review Board (IRB) approval. Consent forms to participate are signed on a volunteer basis but we do not know who is participating until the courses are complete and grades assigned. The consent forms are distributed and stored in both cases by third parties as outlined in the IRB protocol. So, from the onset of each course, participants understand that the professors of these courses are formally engaged in a shared study but that this does not entail any additional student expectations beyond those articulated in each course syllabus. And, the shared study deliberately models the care and vigilance we seek as we position educators throughout each course to confront selves in relation to their curricular practices.

In what follows, first, we discuss the importance of narrative inquiry in creating a space in which teachers' narratives of curricular experiences are heard, with teaching/learning practices being made more visible to themselves and each other. The individual narratives fold into the collective narrative that grows through discussion as we conduct each course and participate alongside all participants. Second, we map out three interrelated themes that permeate the terrain of the collective narrative emerging from our courses. The three themes 
folding into each other that we identify as contributing to the process of forming and enabling teachers' attention to lived curriculum include: 1) Teachers confronting dissonance between theory and practice as teaching identity displacement; 2) Teachers negotiating teaching identity within implacement; and

3) Teachers moving toward embodying the creative space for teaching and learning. We discuss the intersecting themes respectively; and conclude with offering implications for teacher educators. Now we turn to the discussion of narrative inquiry.

\section{Narrative Inquiry}

Lived curriculum requires educators to think outside or beyond the rules and procedures while practicing creative thinking, care, compassion and critical consciousness (Kemmis \& Smith, 2008). It is imperative that teacher educators invest in practices that deliberately foster teachers' creative thinking, care, compassion and critical consciousness. Teacher educators must experiment with ways to access and attend to the relational complexities of teachers' classrooms. Such experimentation cultivates teacher confidence and agency so desperately missing in the current lives of educators. Space must be created for teachers to concretely risk exploring the terrain of lived curriculum.

As Connelly and Clandinin (2006: 477) define narrative as 'the phenomenon studied in inquiy', we turn to teachers' narratives as the phenomenon studied in our inquiry to explore their roles within curricular development and enactment. Narrative inquiry, elucidating personal knowledge (Polanyi, 1974) derived from narratives of experience, has been popular among 
teachers and teacher educators and become an influential research methodology within teacher education (Clandinin et al. 2007; Goodson, 1995). Narrative inquiry is cross-disciplinary and its applications now extend beyond a research methodology, utilized as a pedagogical medium for professional development for pre-service and in-service teachers (Atkinson, 2010; Authors, 2010; Conle, 2000, 2003; Coulter et al. 2007; Denzin \& Lincoln, 2005; Riessman \& Speedy, 2007). Narrative inquiry, indeed, is a maturing field, 'one that refuses a tight set of methodological and definitional prescriptions, but that is still being tilled by members of a community of discourse who sense a certain degree of professional affinity' (Barone, 2010: 152). Both of us feel this professional affinity and collaborate on our teaching of a curriculum course as a means to further understandings of narrative inquiry and its roles in studying educational experience and creating a space to enable lived curriculum.

Narrative inquiry as a pedagogical medium involves an intentional reflexive process of teachers interrogating their own teaching and learning (Lyons \& LaBoskey, 2002). 'Thinking narratively' (Clandinin and Connelly, 2000) is, thus, a fitting way for educators to bring the curriculum course readings to bear on their lived experiences of teaching in their classrooms, chronicling the storied accounts. Individual narratives are shared weekly with opportunities for all to respond. The reconstruction of weekly narratives during class puts everyone in relation to others. As course instructors, we seek ways throughout the evolution of the course for educators to gain insights into their curricular practices and reimagine how their narratives of teaching experience might adapt and change. 
The narrative interchange created has all thinking narratively, as the temporal negotiation of past, present, and future recursively infuses the storied reconstructions.

We draw upon narrative inquiry as a pedagogical medium in which opportunities to concretely navigate lived curriculum as situated, thoughtful and intentional are confronted and developed through inciting theory/practice connectedness, asking course participants' to think narratively about their teaching/learning efforts. It is our intention as the course instructors to illuminate and gain insights into theory/practice relations through engagement with teachers' narratives. As our students who are practicing teachers call into question their practices they initiate their own personal curriculum theorizing alongside engagement with the research literature and alongside participants in graduate level curriculum theory seminars.

Participating educators are asked to theorize and live the language of practice as they examine and express personal understandings of it through encountering, studying, and articulating theory/practice relations where lived curriculum is actively questioned and continually attempted to be brought into being. Narrative inquiry provides a reflexive space for the necessary deliberation. We find reflexivity to be at the heart of thinking narratively. The weekly narrative accounts act as a catalyst for individual thinking, figuring into collective thinking in each seminar group and across both groups, and returning to individual thinking, in an ongoing reflexive discursive movement. The narratives position participants to examine the sense and teaching selves being revealed through reciprocal 
interaction and modification, inciting ways to proceed through greater 'wakefulness' (Clandinin \& Connelly, 2000: 184) of self and other(s). Teaching identities are awakened by the responsive and creative space the narratives offer for exploring the nature of lived curriculum.

As course instructors we understand that gaining insights into lived curriculum requires purposely occasioning reflexive circumstances to foster it. Thus, we attempt to create and nurture opportunities to reflexively examine the consequences of lived theory/practice relations, alongside the input of other educators, valued as productive for everyone's professional growth. In our efforts to do so, an individual/collective movement of thinking grows, giving shape and expression to Dewey's (1938:72) description of such process as necessarily social. The narratives demand that all of us attend to the experiences and understandings of others, and then bring this thinking back to ourselves. Thus, throughout the inquiry the narratives reveal the process character to be interdependent with others. The narratives become the medium that initiate, sustain, and nurture educator wonderings, acting as a catalyst for the movement of thinking that is generated.

In this paper we incorporate teachers' narrative accounts as an integral experience of the curriculum theory seminars, while understanding their narratives as 'the result of a confluence of social influences on a person's inner life, social influences on his or her environment, and his or her unique personal history' (Clandinin \& Murphy, 2009: 599). Through narrative inquiry as a pedagogical medium the courses involve all participants in seeking deeper 
understandings of curriculum and the life it holds, concomitantly promoting teachers' agentic roles within it.

\section{Data Analysis and Discussion}

As researchers we attend to the reflexive interchange created across all data sources, documenting the process, assessing the insights gained and the directions to proceed, on a regular basis. Thus, a reflexive approach (Alvesson \& Skoldberg, 2000) to data collection and analysis is embraced, operating both inductively and deductively throughout. Such a reflexive approach provides means to address the interface between the weekly narratives collected, the interpretations, and the research literature, situating the study and the traditions inherited and being reconstructed. The reflexivity is marked by repetition. Repetition as Risser (1997: 39) explains is 'fundamentally dynamic' entailing the turn and re-turn to self-understandings, acting on possibilities. Risser (1997: 38) elaborates further stating, 'past possibilities of action become future possibilities that are repeated in the moment of decision'. We find that three reflexive moments emerge as thematic intersections modulating the repetitive movement of participating educators seeking out and seizing back possibilities for their curricular practices. These moments arise over and over again through varying perspectives and concrete experiences, with their presence very much shaping the course experiences. The insights generated through reflexive analysis manifest three thematic intersections representing moments of participating educators challenging their teaching identity in both courses. It seems confrontations with de-professionalization make teachers feel out of place. Casey 
(1993) describes a 'placial identity' in which human beings orient and inhabit a place for themselves within the world. He explains that as human beings we constantly position ourselves within physical, social and cultural spheres in which we reside in order to construct our own identities. An embeddedness and belongingness to place, meaningfully embodied within one's identity, reflects 'implacement' while 'displacement' refers to disconnected, disembodied identities. Kincheloe and Pinar (1991: 21) also contend that examining place is a critical tool to link 'particularity to the social concerns of curriculum theory, and analyzing sense of place can serve as a vehicle to self-knowledge. Casey (1993) and Kincheloe and Pinar's (1991) phenomenological notions of place seems very fitting as we consider the teaching identities of participating educators in the narrative inquiry. We explore these intersections for ways educators might problematize, internalize, and enact theorizing efforts, as possibilities enabling lived curriculum.

1. Confronting Theory/Practice Dissonance as Identity Displacement Teachers' narrative accounts provided early in the semester collectively surface much dissonance across participants of both courses, separating educational practitioners from educational theorists and reinforcing the theory/practice dichotomy. Confronting personal dissonance is pervasive for some educators, and for others, the notion resonates immediately. The narrative accounts asking them to elucidate curricular theory/practice relations, initially reinforce the portrayal of practitioners as doers and not as thinkers who are competent to be involved in generating knowledge. Teachers believe that they 
are not capable theorists, or dismiss/distrust theory as something that is irrelevant to their work, and as an impossible undertaking. Representative excerpts from the narratives include:

Theorists do not have the day-to-day responsibilities of the classroom. The classroom teacher is inundated with more and more responsibilities, especially with the pressure of state assessments. There is not time within their daily schedule for planning something new. Theorists do have the time to research and plan and write, but again, the only people who are reading their writings are other theorists. This is a challenge for me. (Artifact \#1, 28/08/07)

I strongly believe what you learn in education courses is far different from what you encounter... The theory courses do not necessarily prepare you for the unexpected or the noted issues of today's society... (Artifact \#3, 4/09/07)

Ayers (1992) emphasizes that theory helps us to 'organize the world, to sort out the details, to make some coherent sense out of a kaleidoscope of sensations; therefore, we would collapse exhausted from our encounter with experience without it' (p. 260). I understood part of this statement; however, I could not truly relate to it because my experiences are far different from what was taught in education classes and what society is facing in education. (Artifact \#4, 4/09/07) 
The narrative excerpts above indicate teachers' confrontation with the felt theory/practice rifts. Teachers do not trust theory as a tool to inform their practice. Teachers refer to theories previously encountered in their undergraduate education programs as being inapplicable and irrelevant to their teaching practices. Teachers talk of how theories are developed by theorists who 'have time to research and plan and write' for 'other theorists'; those who also have time to read and react. The narratives convey over and over again how teachers do not have such time for researching and writing, not to mention time for reading and being up-to-date with current research. They indicate that teachers are 'inundated with more and more responsibilities especially with the pressure of state assessments.' The intensification teachers' narratives describe, typifies the constant meeting of external pressures without sufficient resources or time, including demands from policy-makers and expectations from society (e.g. Apple, 1986; Ballet \& Kelchtermans, 2008). Teachers feel that they 'do more work at home before and after school, and this interferes with their family time and it demands even personal 'sacrifice' as noted in the narrative below:

May (1993, p. 210) describes teaching as a profession that 'requires energy and patience, woven in and unraveling beyond the official time and workspace of school'. This description struck me because that is exactly how I feel at the present time. I have been teaching for eleven years and each year gets harder and harder due to the nature of the environment, type of students, administration, curriculum chosen, and mandates given by the State or Federal Government. It is requiring that I do more work at 
home before and after school, which is interfering with my family time and social realm. I no longer am able to do things I enjoy or spend the time wanted on my endeavors because I am trying to ensure that I do not fail the students or rob them of their learning experience in Biology. However, my life is being sacrificed because I am unable to be involved with my son like I want due to worrying about the pressures on my job, dealing with students that have had poor foundational skills, and negative parental involvement that consists of them making excuses for them and not doing their part in their child's life. (Artifact \#9, 23/10/07)

Teacher narratives reveal a survival mode, implying a separate self that performs as teacher, disconnected from understandings of self, students, and situations. Many of the narratives assert that the concrete realities do not allow teachers to practice the theory. Some teachers respond to these realities by surrendering to simplified, scripted practices in management mode. For example:

Teachers are definitely worried that curriculum is a daily course to be run, especially now with the pressure of high stakes testing. Even at my school, and at my length of time in the field (15 years), my principal still wants me to 'teach to the standards.' He regards the State tested indicators as the material that I should cover, especially in ninth and tenth grade classes. He even arranged for a substitute teacher for my class while I 'learned' how to use an interactive computer program that our school adopted. If I wanted, I could just use the manual to teach my classes. It covers all the tested indicators...so why not? It consists of 
power points and practice questions and practice tests, what else is there? (Artifact \# 8, 19/10/07)

The narratives chronicle educators' collective concern with the question noted above by one of the participating teachers asking, 'What else is there?' We continually draw attention to the relational complexities, the undergoings and doings of specific teaching/learning situations, to consider this persistent question from varied perspectives. The narratives shared throughout the course reveal disconnected teaching identities as educators confront curriculum interpretations as only existing in forms wholly divorced from particular time, place, and people, and as self-contained entities that are captured and represented in pre-specified activities, competencies, and indicators. Consequently, they confront the deprofessionalization experienced in which teachers become the 'executers of other people's decisions' (Ballet \& Kelchtermans, 2008: 2) with little sense of belonging to their teaching/learning practices. Educators' dissonance with theory/practice relations positions them to confront the strained identity investment conveyed within their narratives of teaching and learning. We translate this strained investment as identity displacement.

2. Negotiating Teaching Identity within Implacement It is within participating educators' theorizing process of the undergoings and doings of writing about 'what else is there' concerning their teaching practices that the narratives begin to disrupt and call into question their roles as teachers, positioning them to reconsider why they orient their curricular practices 
in particular ways. Confronting teaching selves and asking themselves who they are in relation to educational theories and pedagogical action, elicits disturbed talk. Questioning their role as an 'executer of other people's decisions' becomes 'troubling knowledge' that is disruptive and disturbing. According to Kumashiro, troubling knowledge paradoxically works to help teachers see 'what different insights, identities, practices, and changes it makes possible while critically examining that knowledge (and how it came to be known) to see what insights, etc., it closes off' (Kumashiro, cited in Pinar, 2007: 64). As teachers question the troubling knowledge, they begin to problematize their displacement and negotiate toward implacement. The notion of implacement is fitting for the teaching identities we see awakened through active and operative narrative engagement with/within their teaching/learning practices. The weekly narrative accounts written by educators deliberately attempting to make personal connections across their teaching practices and the education research literature become spaces for articulating and locating teaching identities, individually and collectively. For example, the following teachers' narratives reveal greater realization of place and who they are in relation to other(s), an indication of teaching identities seeking implacement:

Ayers (1992) states that schools 'turn teachers into clerks, that curriculum is the product of someone else's thought, knowledge, experience, and imagination' (p. 260) This is so true, and so sad. I did not like the statement though, that we are only 'line employees doing our job'. Another thought-provoking phrase, 'the machinery of schooling' (p. 261) caused 
me some consternation. Have we come to that? Have I? (Artifact \# 5, 4/09/07)

The impact of scientific management on teacher autonomy suggests that teachers are prevented from deciding what is the most valuable to teach and how to teach it. I totally disagree with this. Teachers are professionals and have professional judgment about their students and their classroom. (Artifact \# 7, 9/10/07)

This is why I choose to theorize practice in my classroom. I was unhappy that teachers are not considered theorizers. Perhaps a better term is offended that teachers are not considered 'bright' enough. (Artifact \# 2, 28/08/07)

Teachers question practices that turn them into 'clerks,' and find the notion unpleasant, disagreeable and offensive. They identify themselves as professionals who ought to be making the judgments about their students and their classrooms. The collective task of continually questioning the troubling knowledge becomes a task of participation in understanding one's teaching identity, negotiating implacement. We turn to Risser for insights. Risser (1997:116) emphasizes participation is not simply a 'going along; rather in participation, we become vigilant to the question' interrogating the troubling knowledge. Such vigilance is what individual educators explore through participatory thinking, actively engaging in creating meaning, demanding 
presence within moments through taking in, receiving, and acting, as teaching/learning situations call forth.

We observe teachers' collective efforts at vigilance, attending to selfunderstanding while listening to others' narratives, to entail revising and revisiting their individual narratives. Their personal learning reflections as students themselves are recalled and serve as one vehicle. Grappling with the lived teaching/learning terms of relationality, and its accompaniments of responsivity and creativity, becomes the necessary teaching identity negotiation integral within implacement.

In the process of negotiating implacement, teachers seriously pursue their teaching/learning as relational practices and their narratives document more and more wonder regarding the undergoings and doings of what else is there within the given complexities of classrooms. Hansen (2001) terms this 'teaching indirectly' with the pedagogical focus becoming the relations of students, context, subject matter, and teacher, forming and re-forming learning situations as shown in the narrative excerpts as follows:

How will students tell me what they know? How much they know, when they know, why they know, and how? Do they explain in a paper or communicate through a presentation or interview? Do they write down problems and show all their steps? What counts? How much is enough? How will grades be assigned? (Artifact \#10, 25/10/07) 
I am seeing more and more within each moment in my classroom. It can be overwhelming if you think about it too long. But, I am catching myself as I teach and really trying to listen to my students. I am listening through their spoken words but also through their expressions and body language, their assignments, and the closer I listen I find myself teaching in unexpected ways. The other day after carefully planning out a lesson and mapping out the unit with my teaching team, I found myself abandoning the scripted direction and following through with students' wonderings about texture in an art lesson with my grade 3 students. (Artifact $\# 13,12 / 11 / 07)$

Seeing and acting on the relational complexities to further learning becomes the teaching task. The narratives repeatedly depict teachers wrestling with why they should see and act accordingly resulting in 'abandoning the scripted direction and following through with students' wonderings.' Negotiating teaching identity within implacement occurs through teachers' vigilant participation in decision-making and increasing cognizance of the reciprocal interchange across teacher, students, subject matter, and context.

3. Learning to Embody the Creative Space for Teaching/Learning As teachers negotiate their teacher identity integral within implacement, they gain access to the creative space of lived curriculum. O'Loughlin (2006) explains that an implaced body is not a subject or object but always seeking connections with its surroundings; concomitantly perceiving and receiving. $A$ teaching identity takes hold that is not grounded in a solitary consciousness, but 
rather a developing consciousness of a consciousness always in relation to other(s). Teachers' narratives reveal teaching and learning newly experienced as reciprocal, in flux, and situated. Such reciprocity entails teachers being at the juncture of the movement between self and other. Merleau-Ponty (1964) describes this juncture as a 'crisscrossing'; neither subject nor otherness are bound entities, they intermingle. Crisscrossing demands mindfully embodied teaching identities, in touch with context, finding accordance within lived curricular experience. Examples include:

I like the idea of teaching as a living thing. I have been using a journal assignment with my students to help me understand their viewpoints and respond personally to each one. I have felt an energy and enthusiasm released in students and myself. Lately, though, with district pressures to record and document specific learning goals and their achievement, I have let the journals become less about personal student learning and more about my accountability to the predetermined goal statements. I am going to rectify this. (Artifact \#9, 30/10/07)

I think that teachers need to be participatory just as we want our students to participate in their education. We continue to learn, just as they do. And if we do not practice what we learn then we lose opportunities to reach our students. (Artifact \#11, 30/10/07) 
I was hegemonized by the textbook companies, and I believed, as Janet Miller explains, that there were discrepancies between what I learned in my teacher preparation program and what I was encountering in my daily teaching (Miller, 1992)... According to Ayers, I had become a consumer of the package of curriculum, passive, and dependent (Ayers, 1992). And I taught with this mindset for seventeen years...As I have grown as a professional, I now realize that the theory of social constructivism continues to change my practices. (Artifact \#14, 27/11/07)

As an educator at first it seemed harsh to read about our education system "dedicated to the production of useless things" (Sidorkin, 2002). I had never thought or questioned the nature of education in that way. I thought about how I think about motivation as external strategies toward production and Sidorkin and others caused me to question where internal motivation existed within learning. The way we teach and how we teach relates directly back to our students whether we are teaching coil pot construction in pottery or matters of physical science. The reasons we are teaching are extremely important to embody. (Artifact \#6, 06/09/07) The intersecting moments of teaching identity displacement, negotiating implacement, and embodying the creative space of praxis appear to awaken participating teachers and return teaching and learning to its original complexity (Caputo, 1987). As teachers seek more organic connections within their teaching practices the narratives collectively evidence that embodied understandings are 
inaugural to lived curriculum. Mindful embodiment reciprocally connects teachers to place, belonging as much to the other (context) as to self. In this way the teaching body is the place for the conjuncture of theory and practice to translate teaching/learning as situated, thoughtful, and intentional, encountered through what O'Loughlin (2006:82) terms 'multi-sensory engagement'. The narratives enable individual teachers to inhere in the sensible, reorienting teaching and learning toward creating meaning. Collectively, the narratives draw attention to learning complexities and differences, and evoke individual teacher willingness and susceptibility to address them. The narratives give greater visibility to the negotiation of embodied teaching identities increasingly mindful of the concrete undergoings and doings of their practices while seeking relations within the research literature. These narratives fold into each other and the ensuing reciprocal interaction and modification holds the 'creative power' (O'Loughlin, 1995: 3). An individual/collective movement of thinking, increasingly made visible and tangible, manifests itself. Narratives convey teaching identities unleashing a creative teaching agency. A representative teacher narrative is as follows: I am thinking of teaching as constantly reading situations and students and taking this information to inform the way learning looks and feels. The more I attempt to do so, the more I see, and I enjoy the liberation I experience and the unexpected directions my classes have taken. Students seem to feel this too. I did not realize the power of creativity in teaching/learning practices. I held dearly to tightly controlling the science learning in my classroom. I carefully orchestrated every moment and 
every movement. I would go so far to say that the classroom felt tense. I discussed this with students and we talked about the nature of inquiry within science. I have asked them to be inquirers with me and I am extremely surprised by how purposefully they have embraced inquiry. I have totally shaken up the ways learning looks in my classroom. It has been much work but the teaching has felt much more invigorating. And, I am living less fearfully, less tensely, in my classroom. (Artifact 21, 05/12/07)

\section{Conclusion: Renewed Roles for Teacher Educators \& Curriculum Theorists}

The narrative thinking generated throughout our graduate course experiences reveal to all of us that teachers feel displaced, disconnected, and incapacitated, rendering the complicated conversations of lived curriculum to be endangered. However, as they engage in course readings, conversations, and weekly narrative practices, they start negotiating between displacement and implacement, moving toward embodying the creative space for teaching, learning, and curriculum theorizing, undergirding the cultivation of these conversations.

It seems the narrative theorizing accounts help to bring teachers near to their practices. The narrative accounts confront and challenge beliefs alongside affirming beliefs. As teachers discuss their narratives in small groups they hear similar stories/different stories and each narrator continually confronts self in relation to situations. As teachers engage with each other's narratives, the research literature, and bring this thinking back to bear on their own narrative 
accounts, they find themselves acquiring an empowering/liberating language that clarifies and articulates undergirding values, assumptions, and beliefs about teaching identity in relation to their curricular practices. As they grapple with the many unfolding ideas through narratives, they actively participate in the theorizing process through questioning, challenging, confronting, imagining, voicing, integrating, internalizing, clarifying, vivifying, and embodying. It seems narrative inquiry generates a space for teachers to theorize their educational practices in search of lived theory. Through narrative inquiry, teachers negotiate implaced teaching, translating teaching as theorizing spaces.

Renewed roles for teacher educators and curriculum theorists are brought to our attention throughout our study. First, the importance of teacher educators working alongside teachers is revealed, encouraging each other to tease out understandings of teaching and learning through their narratives and enabling greater teaching agency. In this renewed role, we find narrative inquiry to be a powerful pedagogical medium for occasioning and developing lived curriculum in the lives of educators. It fosters professional identities that claim the creative space of teaching/learning (Authors, 2010), positioning all of us to reconsider and renegotiate our teaching identities, concomitantly creating meaning and creating self, instilling complicated curricular conversations as integral within teaching/learning.

Second, teacher educators and curriculum theorists must confront and critically explore the constraints of lived curriculum within given particular contexts. Teacher educators might ask themselves such questions as: How are 
we collaborating with practicing teachers to reframe mandated policies and initiatives undermining the work of teaching and learning as situated, thoughtful and intentional? How are we collaborating with teachers to think about imposed policies/initiatives differently, moving beyond tolerating mandates that curtail their efforts? In what ways are we occasioning meaningful opportunities for practicing teachers to develop their professional identities? Investing in lived curriculum entails purposefully creating contexts for professional learning. Teacher educators must assume leadership roles for supporting and advocating for the learning contexts that best enable lived curriculum within the particularities of given contexts.

Finally, we urge that teacher educators and curriculum theorists claim the responsibility to provide the intellectual, emotional, and pragmatic spaces where teachers' lived curriculum efforts can be developed and nurtured. As Hiebert et al. (2002) point out the process character of change in professional development has been neglected. Olson and Craig (2001) concur that little attention is paid to the agency of teachers and to the nature of how teachers learn based on their personal practical knowledge. Thus, as Easton (2008: 755) declares professional development becomes merely 'what someone does to others' and fails to orient teachers to be purposefully involved as primary participants. Our attempt to do just this aligns with other more constructivist orientations focusing on 'how' teachers learn rather than 'what' teachers learn (e.g., Easton, 2008; Groundwater-Smith \& Mockler, 2009; Jenlink \& Kinnucan-Welsch, 2001). These attempts focus on teacher learning while drawing across multiple research 
traditions and approaches, attending to the particularities of contexts, and emphasizing teacher research (O'Connell Rust, 2009). Teacher educators committed to the formative nature of teaching and learning and professional knowledge must assume responsibility for forming communities of professionals who consciously and continuously act and interact with integrity and agency for student learning.

Pinar (2009: 11) claims that the past 40 years of preoccupation with evaluative educative measures have led to 'institutional neglect of the intellectual quality and character of the curriculum'. The renewed roles for teacher educators and curriculum theorists that we identify, refocus attention on the dire consequences of this neglect alongside the needs to continually foster the supports and nurture the conditions that enable teachers to respond sensitively and wisely to further learning within the demands of given teaching/learning situations. We saw evidence of teachers 'reintegrating teaching into the concept of curriculum...' putting ' the teacher in his or her place: a participant in an ongoing multi-referenced conversation (Pinar, 2009: 11). Narrative inquiry as a pedagogical medium brought both of us, alongside our students, much nearer to this needed place. 


\section{References}

Alvesson, M., \& Skoldberg, K. (2000) Reflexive Methodology (London: Sage).

Apple, M. W. (1986) Teachers and Texts: A Political Economy of Class and Gender Relations in Education (London: Routledge).

Atkinson, B. (2010) Teachers responding to narrative inquiry: An approach to narrative inquiry criticism. Journal of Educational Research, 103(2), 91102.

Ayers, W. (1992) The shifting ground of curriculum thought and everyday practice. Theory into Practice, 31(3), 259-263.

Ballet, K., \& Kelchtermans, G. (2008) Workload and willingness to change: Disentangling the experience of intensification. Journal of Curriculum Studies, 1-21.

Barone, T. (2010) Commonalities and variegations: Notes on the maturation of the field of narrative research. Journal of Educational Research, 103(2), 149-153.

Caputo, J. D. (1987) Radical Hermeneutics: Repetition, Deconstruction and the Hermeneutic Project (Bloomington: Indiana University Press).

Casey, E. S. (1993) Getting Back into Place: Toward a Renewed Understanding of the Place-world (Bloomington \& Indianapolis: Indiana University Press).

Clandinin, D. J. \& Connelly, F. M. (2000) Narrative Inquiry: Experience and Story in Qualitative Research (San Francisco: Jossey-Bass). 
Clandinin, D. J. \& Murphy, M. S. (2009) Relational ontological commitments in narrative research. Educational Researcher, 38 (8), 598-602.

Clandinin, D. J., Pushor, D., \& Orr, A. M. (2007) Navigating sites for narrative inquiry. Journal of Teacher Education, 58(1), 21-35.

Conle, C. (2000) Narrative Inquiry: Research tool and medium for professional development. European Journal of Teacher Education, 23(1), 49-63.

Conle, C. (2003) An anatomy of narrative curricula. Educational Researcher, 32(3), 3-15.

Connelly, F. M., \& Clandinin, D. J. (2006) Narrative inquiry. In J. L. Green, G. Camilli \& P. Elmore (eds), Handbook of Complementary Methods in Education Research, 3rd ed. (Mahwah, NJ: Lawrence Erlbaum), 477-487.

Coulter, C., Michael, C., \& Poynor, L. (2007) Storytelling as pedagogy: An unexpected outcome of narrative inquiry. Curriculum Inquiry, 37(2), 103122.

Denzin, N., \& Lincoln, Y. (2005) Introduction. In N. Denzin \& Y. Lincoln (eds), The Sage Handbook of Qualitative Research (Thousand Oaks, CA: Sage), 1-29.

Dewey, J. (1934) Art as Experience (New York: Capricorn Books).

Dewey, J. (1938) Experience and Education (New York: Continuum).

Easton, L. B. (2008) From professional development to professional learning. Phi Delta Kappan, 89(10), 755-759. 
Goodson, I. (1995) The story so far: Personal knowledge and the political. In J.

A. Hatch \& R. Wisniewski (eds), Life History and Narrative (London:

Falmer Press), 86-97.

Groundwater-Smith, S. \& Mockler, N. (2009) Teacher Professional Learning in an Age of Compliance (UK: Springer).

Hansen, D. T. (2001) The Moral Heart of Teaching: Toward a Teacher's Creed (New York: Teachers College Press).

Hargreaves, A. \& Shirley, D. (2009) The persistence of presentism. Teachers College Record, 111(11) 2502-2534.

Hiebert, J., Gallimore, R., \& Stigler, J. (2002) A knowledge base for the teaching profession: What would it look like and how can we get one? Educational Researcher, 31(5) 3-15.

Jenlink, P. M., \& Kinnucan-Welsch, K. (2001) Case stories of facilitating professional development. Teaching and Teacher Education, 17(6), 705724.

Kemmis, S., \& Smith, T. (2008) Enabling Praxis: Challenges for Education (Rotterdam: Sense Publishers).

Kincheloe, J. L., \& Pinar, W. F. (1991) Curriculum as Social Psychoanalysis: The Significance of Place (Albany, NY: State University of New York Press).

Lortie, D. C. (1975) Schoolteacher: A Sociological Study (Chicago: Univeristy of Chicago Press).

Lyons, N., \& LaBoskey, V. K. (2002) Why narrative inquiry or exemplars for a 
scholarship of teaching? In N. Lyons \& V. K. LaBoskey (eds), Narrative Inquiry in Practice: Advancing the Knowledge of Teaching (New York: Teachers College Press), 11-30.

Malewski, E. (2010) (ed) Curriculum Studies Handbook: The Next Moment (New York: Routledge).

May, W. (1993) Teaching as a work of art in the medium of curriculum, Theory Into Practice, 32 (4), 210-218.

Merleau-Ponty, M. (1964) Signs (Evanston: Northwestern University Press).

Miller, J. L. (1992) Shifting the boundaries: Teachers challenge contemporary curriculum thought. Theory into Practice, 31(3), 245-251.

O'Connell Rust, F. (2009) Teacher research and the problem of practice. Teachers College Record, 111 (8), 1882-1893. http://www.tcrecord.org ID Number: 15446, Date Accessed: 12/29/2009.

O'Loughlin, M. (1995) Intelligent bodies \& ecological subjectivities: MerleauPonty's corrective to postmodernism's "subjects" of education. In A. Neiman (ed.), Philosophy of Education Society Yearbook (UrbanaChampaign: University of Illinois).

O'Loughlin, M. (2006) Embodiment and Education: Exploring Creatural Existence (Dordrecht, The Netherlands: Springer).

Olson, M. R., \& Craig, C. (2001) Opportunities and challenges in the development of teachers' knowledge: The development of narrative authority through knowledge commmunities. Teaching and Teacher Education, 17(6), 667-684. 
Pinar, W. F. (2007) Intellectual Advancement through Disciplinarity: Verticality and Horizontality in Curriculum Studies (Rotterdam: Sense Publishers).

Pinar, W.F. (2009) The Worldliness of a Cosmopolitan Education: Passionate Lives in Public Service (New York: Routledge).

Polanyi, M. (1974) Personal Knowledge: Towards a Post-critical Philosophy (Chicago: The University of Chicago Press).

Riessman, C. K., \& Speedy, J. (2007) Narrative inquiry in the psychotherapy professions. In D. J. Clandinin (ed), Handbook of Narrative Inquiry: Mapping a Methodology (Thousand Oaks, CA: SAGE Publications), 426456.

Risser, J. (1997) Hermeneutics and the Voice of the Other: Re-reading Gadamer's Philosophica Hermeneutics (New York: State University of New York Press).

Sidorkin, A. (2002) Learning Relations: Impure Education, Deschooled Schools, \& Dialogue with Evil (New York: Peter Lang).

Smith, D. G. (2006) Trying to Teach in a Season of Great Untruth: Globalization, Empire, and the Crises of Pedagogy (Rotterdam, The Netherlands: Sense Publishers).

Uhrmacher, P.B. \& Mathews, J. (2005) Intricate Palette: Working the Ideas of Elliot Eisner (Upper Saddle River, New Jersey: Pearson, Merrill Prentice Hall). 